Research paper

\title{
Modulation of bone marrow mesenchymal stem cell secretome by ECM-like hydrogels
}

\author{
Nuno A. Silva a,b,1, Joana Moreira a,b,1, Silvina Ribeiro-Samy ${ }^{\mathrm{a}, \mathrm{b}}$, Eduardo D. Gomes ${ }^{\mathrm{a}, \mathrm{b}}$, \\ Roger Y. Tam ${ }^{\mathrm{d}, \mathrm{e}}$, Molly S. Shoichet ${ }^{\mathrm{d}, \mathrm{e}, \mathrm{f}}$, Rui L. Reis ${ }^{\mathrm{b}, \mathrm{c}}$, Nuno Sousa ${ }^{\mathrm{a}, \mathrm{b}}$, António J. Salgado ${ }^{\mathrm{a}, \mathrm{b}, *}$ \\ ${ }^{a}$ Life and Health Sciences Research Institute (ICVS), School of Health Sciences, University of Minho, Campus de Gualtar, 4710-057 Braga, Portugal \\ ${ }^{\mathrm{b}}$ ICVS/3B's - PT Government Associate Laboratory, Braga/Guimarães, Portugal \\ ' 3B's Research Group - Biomaterials, Biodegradables and Biomimetics, University of Minho, Headquarters of the European Institute of Excellence on Tissue \\ Engineering and Regenerative Medicine, AvePark, Caldas das Taipas, 4806-909 Guimarães, Portugal \\ ${ }^{\mathrm{d}}$ Department of Chemical Engineering and Applied Chemistry, University of Toronto, 200 College Street, Toronto, ON M5S 3E5, Canada \\ e Institute of Biomaterials and Biomedical Engineering, 164 College Street, Room 407, Toronto, ON M5S 3G9, Canada \\ ${ }^{\mathrm{f}}$ Department of Chemistry, University of Toronto, 80 St. George Street, Toronto, ON M5S 3H6, Canada
}

\section{A R T I C L E I N F O}

\section{Article history:}

Received 15 May 2013

Accepted 6 August 2013

Available online 30 August 2013

\section{Keywords:}

Hydrogels

Mesenchymal stem cells

Extracellular matrix

Secretome

Neurons

\begin{abstract}
A B S T R A C T
It has been demonstrated that bone marrow mesenchymal stem cell (BM-MSCs) transplantation has beneficial effects on several central nervous system (CNS) debilitating conditions. Growing evidence indicate that trophic factors secreted by these cells are the key mechanism by which they are acting. These cells are frequently used in combination with 3D artificial matrices, for instance hydrogels, in tissue engineering-based approaches. However, so far, no study has been reported on the influence of such matrices, namely the presence or absence of extracellular matrix motifs, on BM-MSCs secretome and its effects in neuronal cell populations. In this sense, we herein studied the impact of a hydrogel, gellan gum, on the behavior and secretome of BM-MSCs, both in its commercial available form (commonly used in tissue engineering) and in a fibronectin peptide-modified form. The results showed that in the presence of a peptide in the gellan gum hydrogel, BM-MSCs presented higher proliferation and metabolic activity than in the regular hydrogel. Moreover, the typical spindle shape morphology of BM-MSCs was only observed in the modified hydrogel. The effects of the secretome of BM-MSCs were also affected by the chemical nature of the extracellular matrix. BM-MSCs cultured in the modified hydrogel were able to secrete factors that induced higher metabolic viabilities and neuronal cell densities, when compared to those of the unmodified hydrogel. Thus adding a peptide sequence to the gellan gum had a significant effect on the morphology, activity, proliferation and secretome of BM-MSCs. These results highlight the importance of mimicking the extracellular matrix when BM-MSCs are cultured in hydrogels for CNS applications.
\end{abstract}

(C) 2013 Published by Elsevier Masson SAS

\section{Introduction}

Mesenchymal stem cells (MSCs) are particularly appealing for regenerative medicine applications because they are easy to isolate and expand, do not pose any serious ethical or technical problems, and can be used for autologous approaches, without the risk of tumor formation. MSCs derived from the bone marrow (BM-MSCs) are perhaps the most widely applied in regenerative approaches,

\footnotetext{
* Corresponding author. Life and Health Sciences Research Institute (ICVS), School of Health Sciences, University of Minho, 4710-057 Braga, Portugal. Tel.: +351 2536049 47; fax: +351253604820.

1 These authors contributed equally to this work.
}

including cardiac [1], bone [2], neural [3], cartilage [4], lung [5] and meniscus [6] related applications. In recent years it has been shown that the possible therapeutic potential of these cells is closely related to their secretome, which includes growth factors, microvesicles and exosomes to the extracellular milieu [7]. In fact, several reports have revealed that BM-MSCs secretome can be a potent regulator of neuronal differentiation and survival [8-10].

However, the low survival rate of BM-MSCs upon transplantation is still a major hurdle regarding their clinical application for CNS related strategies. One possible route to follow would be the combination of MSCs with biomaterials through tissue engineering based methodologies. Tissue engineering is an interdisciplinary field that usually combines cells and biomaterials in order to restore or improve tissue function [11]. The biomaterial plays a 
central role in any tissue engineering approach and should be carefully chosen. It is commonly accepted in this field that the biomaterials should be able to act as a substrate for the initial phase of cell adhesion [12], promote proliferation [13], and temporarily act as a mechanical support for tissue regeneration [14]. For CNS related applications hydrogels are particularly compelling because they can uniformly disperse living cells or drugs into the affected tissue and have CNS tissue-like mechanical properties $[15,16]$. Although the combination of BM-MSCs with different hydrogels has been proposed by others [17-19], the effect of the biomaterial on the secretome of MSCs has been ignored. As the latter plays a central role in the therapeutic properties of MSCs, understanding how the biomaterial modulates MSC secretome is critical.

In the present work we aimed at determining how the modification of a hydrogel with an extracellular matrix derived peptide (GRGDS) could influence the BM-MSCs morphology, activity and secretome. For this purpose a linear anionic microbial polysaccharide composed of repeating units of glucose, glucuronic acid and rhamnose named gellan gum (GG) was used [20]. This hydrogel, and its derivatives, has previously shown to be favorable for cartilage and disc repair/regeneration [21,22]. Moreover, it was previously demonstrated that, by using Diels-Alder click chemistry, the GRGDS fibronectin-derived peptide could be immobilized to gellan gum hydrogels and that these peptide-modified gellan gum gels promoted greater adhesion and proliferation of neural stem/progenitors cells (NSPCs) than gellan gum controls [23]. Results revealed that the presence of the peptide enhanced cell BMMSCs proliferation, metabolic activity and cell morphology. Moreover, we also demonstrate that click-conjugated GRGDS-gellan gum positively modulates the BM-MSCs secretome, which enhanced the survival and differentiation of primary cultures of hippocampal neurons in vitro.

\section{Materials \& methods}

\subsection{Functionalization of the gellan gum hydrogel with the GRGDS peptide}

The gellan gum hydrogel was modified with the fibronectinderived peptide as previously described [23]. Briefly, gellan gum (Sigma, USA) was first dissolved in 2-( $N$-morpholino) ethanesulfonic acid (MES) buffer (100 mM, pH 5.5) at $37{ }^{\circ} \mathrm{C}$. 4-(4,6Dimethoxy-1,3,5-triazin-2-yl)-4-methylmorpholinium chloride (DMT-MM, Sigma, USA) and furfurylamine (Acros Organics, Belgium) were then added in a $4: 1 \mathrm{M}$ ratio (of each reagent relative to the $-\mathrm{COOH}$ groups in gellan gum) and stirred at $37{ }^{\circ} \mathrm{C}$ for $48 \mathrm{~h}$. The solution was then dialyzed ( $M_{\mathrm{w}}$ cutoff $12-14 \mathrm{kDa}$, Spectrum Labs, USA) alternately against distilled water and PBS (0.1 M, pH 7.2) for 5 days. Water was then removed by lyophilization to obtain furan-modified gellan gum (furan-GG) as a white powder. Subsequently, the immobilization of maleimidecontaining GRGDS peptide (mal-GRGDS, AnaSpec, USA) to furanmodified gellan gum was performed via Diels-Alder chemistry between the maleimide functional group of the peptide with the furan group of the gellan gum. Furan-GG was first dissolved in MES buffer (100 mM, pH 5.5) at $37^{\circ} \mathrm{C}(4 \mathrm{mg} / \mathrm{ml})$. Mal-GRGDS was then added in a 5:1 maleimide:furan molar ratio and vigorously stirred for $48 \mathrm{~h}$ at $37^{\circ} \mathrm{C}$. The solution was then dialyzed $\left(M_{\mathrm{w}}\right.$ cutoff $12-14 \mathrm{kDa})$ alternately against distilled water and PBS $(0.1 \mathrm{M}, \mathrm{pH}$ 7.2 ) for 5 days. Finally, the water was removed by lyophilization to obtain GRGDS-modified Gellan Gum (GG-GRGDS) as a white powder. It was previously reported by us that, by using this protocol, it is possible to obtain a peptide-modified hydrogel with approximately $300 \mathrm{nmol}$ of GRGDS peptide covalently bound to each milligram of gellan gum [23].

\subsection{BM-MSCs culture}

BM-MSCs, acquired from PROMOCELL (Switzerland), were cultured in $\alpha$-MEM (Invitrogen, USA) supplemented with 10\% FBS and $1 \%$ antibiotic-antimycotic mixture. The culture medium was changed every $2 / 3$ days. Upon confluence, cells were trypsinized and passaged to new T75 flasks.

\subsection{Cell encapsulation and conditioned medium collection}

BM-MSCs were encapsulated in the modified gellan gum hydrogel as previously described [24]. Briefly, the gellan gum powder, either GRGDS-modified or regular, was dissolved in ultrapure water $(0.5 \%, \mathrm{w} / \mathrm{v})$ at $40^{\circ} \mathrm{C}$ for $1 \mathrm{~h}$. Then, PBS $10 \times$ was added to the gel solution in order to start the gelification process. Cells were then encapsulated in the hydrogel at the concentration of $5 \times 10^{5}$ cells $/ \mathrm{ml}$. Subsequently, triplicates with $100 \mu$ l of hydrogel each were cultured during 7 days using chambered coverglass (ThermoScientific, USA).

After 7 days in culture, the BM-MSCs encapsulated in the hydrogels were washed 5 times with PBS and then incubated with neurobasal-A serum-free medium (Invitrogen) for $24 \mathrm{~h}$. Upon conditioning, the medium was incubated with neuronal primary cells.

\subsection{Hippocampal neuronal cultures}

Primary cultures of hippocampal neurons were prepared as previously described [10]. Briefly, the hippocampi of P4 Wistar rats were dissected and submitted to trypsin-based enzymatic digestion and mechanical dissociation. Isolated cells were then platted on poly-D-lysine-coated coverslips at a density of $4 \times 10^{4} \mathrm{cells} / \mathrm{cm}^{2}$ and allowed to grow for 7 days. Then, the neuronal cultures were incubated with the previously collected conditioned medium for 7 days (with half of the volume of conditioned medium being renewed at day 4 of culture), after which cell densities, viability and proliferation were assessed. Besides kanamycin $(0.1 \mathrm{mg} / \mathrm{ml}$, Invitrogen) and glutamax (1 mM, Invitrogen), no further supplements were added to the BM-MSCs conditioned medium. Positive control cultures were kept in neurobasal medium supplemented with kanamycin, glutamax, bFGF (10 ng/ml, Invitrogen) and B27 (2\%, Invitrogen).

\subsection{Metabolic activity assay}

Cell metabolic viability was measured using the CellTiter $96^{\circledR}$ Aqueous One Solution Cell Proliferation Assay (Promega, USA) as previously described [25]. This assay is based on the bioreduction of a tetrazolium compound (MTS), into a water-soluble brown formazan product. This conversion is accomplished by NADPH or NADH production by the dehydrogenase enzymes in metabolically active cells. Complete culture medium was replaced by standard basal medium containing MTS in a 5:1 ratio and incubated in a humidified atmosphere at $37{ }^{\circ} \mathrm{C}$ and $5 \% \mathrm{CO}_{2}$. After $3 \mathrm{~h}$ of incubation, the optic density for triplicates of each sample $(n=3)$ was measured at $490 \mathrm{~nm}$ in a microplate reader.

\subsection{Proliferation evaluation}

The cell proliferation was assessed through double-stranded DNA quantification. Briefly, after cell lysis by osmotic and thermal shock three components of QuantiTTM PicoGreen dsDNA Assay Kit (Invitrogen), Tris-HCl-EDTA (50\%), Picogreen dye (35,45\%) and cell lysated (16,35\%), were mixed in an opaque 96 well plate. The fluorescent intensity, proportional to the amount of dsDNA, was 
measured at an excitation wavelength of $485 / 20 \mathrm{~nm}$ and at an emission wavelength of $528 / 20 \mathrm{~nm}$, in a microplate reader (BioTek). The dsDNA concentration for triplicates of each sample $(n=3)$ was calculated using a standard curve relating quantity of dsDNA and fluorescence intensity.

\subsection{Immunocytochemistry and phalloidin/DAPI staining}

The following primary antibodies were used for the immunocytochemical studies: monoclonal mouse anti-GFAP (Chemicon) for astrocytes and monoclonal mouse anti-MAP2 (Sigma-Aldrich) for neurons. For all immunocytochemical procedures, the appropriate controls were obtained by omission of the relevant primary antibody. Cells on the substrates were fixed with PBS solution containing 4\% paraformaldehyde (PFA) for $20 \mathrm{~min}$ (on glass) or $1 \mathrm{~h}$ (on the hydrogel) at room temperature and then washed with PBS. After cell membrane permeation and blocking by treating with $0.3 \%$ Triton X-100 (Sigma, USA) and 10\% of FBS solution at room temperature for $1 \mathrm{~h}$, each specific primary antibody solution was added for $1 \mathrm{~h}$. After washing with $0.5 \%$ of FBS in PBS, the samples were exposed to the specific secondary antibody (Invitrogen) for $1 \mathrm{~h}$ and then washed with $0.5 \%$ FBS. Finally, cell nuclei were counterstained with $1 \mu \mathrm{g} / \mathrm{ml}$ DAPI (Invitrogen) for $10 \mathrm{~min}$.

For the phalloidin/DAPI staining, cells were fixed with 4\% PFA for $30 \mathrm{~min}$ at room temperature and then treated with $0.3 \%$ Triton X100. After PBS washing, $0.1 \mu \mathrm{g} / \mathrm{ml}$ of phalloidin (Sigma) was added to the cells during $30 \mathrm{~min}$. Finally, cell nuclei were counterstained with DAPI ( $1 \mu \mathrm{g} / \mathrm{ml}$, Invitrogen) for $10 \mathrm{~min}$.

\subsection{Statistical analysis}

All statistical analyses were performed using GraphPad Prism version 5.00 for Windows (GraphPad Software, USA). Differences among groups were assessed by $t$-test. A $p$-value of $\leq 0.05$ (95\% confidence level) was set as the criteria for statistical significance. All data are presented as mean \pm standard deviation.

\section{Results \& discussion}

In the present work we aimed at understanding if the presence or absence of an ECM derived peptide on gellan gum hydrogels could induce changes on the effects caused by BM-MSCs secretome on hippocampal neuronal cell populations.

BM-MSCs were encapsulated within GRGDS-Gellan Gum (GRGDS-GG) and compared to BM-MSCs cultured in unmodified GG hydrogels. Cell metabolic activity and proliferation were assessed after 7 days of culture. The results revealed distinct differences in BM-MSCs behavior when cultured in the peptidemodified hydrogel relative to the unmodified hydrogel. When encapsulated in GG-GRGDS, BM-MSCs were able to migrate and successfully expand throughout the hydrogel; moreover, they reveal a typical spindle like cell morphology (Fig. 1a). In contrast, BM-MSCs cultured into the unmodified GG were unable to expand and did not present their characteristic morphology (Fig. 1b). Analysis of the BM-MSCs proliferation also revealed that cells cultured on GRGDS-modified hydrogels are able to proliferate to a significantly higher extent $(p<0.05)$ than cells cultured on unmodified hydrogels (Fig. 1c). In addition, the viability of these cells was also significantly higher $(p<0.001)$ than the viability of cells grown in the absence of the peptide (Fig. 1d). The higher metabolic activity may be due to the higher number of cells and not to a direct effect of the peptide. Nevertheless, it is important to notice that as previously described by Hutmacher et al., [26] the quantification of metabolic activity in three dimensional cultures by MTS test cannot be directly compared with proliferations assays, such as the dsDNA assays. Actually, while the latter are based on the Picogreen assay, which is a sensitive test that can be correlated with proliferation of cells with time, MTS relies only in the capability of cells to

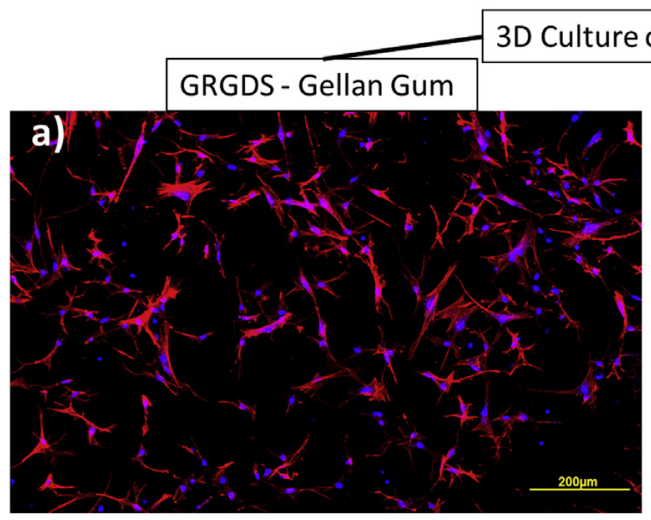

c)

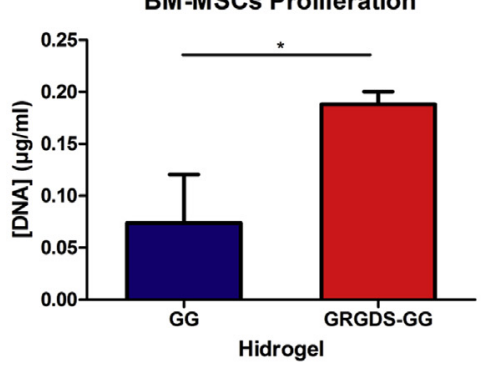

Regular Gellan Gum

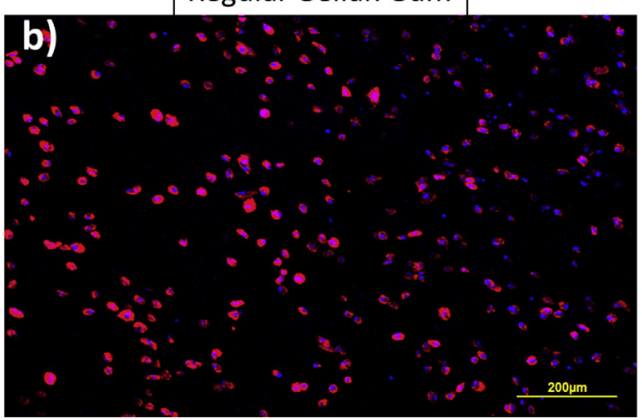

d)

BM-MSCs Metabolic Activity

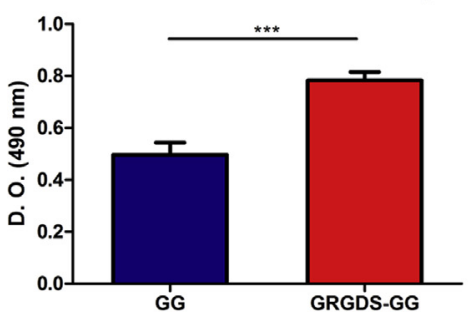

Fig. 1. The effect of peptide modified gellan gum on the morphology, proliferation and activity of BM-MSCs. After 7 days in culture, the cytoskeleton of BM-MSCs cultured on (a) GRGDS-GG and (b) regular gellan were stained with phalloidin (red) and nuclei counterstained with DAPI (blue). Cells cultured on peptide modified hydrogel presented significantly higher (c) proliferation and (d) metabolic activity. Scale bar: $200 \mu \mathrm{m}$. Values are shown as mean \pm standard deviation $\left(n=3\right.$ samples of $5 \times 10^{4}$ cells/sample, ${ }^{*} p<0.05$; ${ }^{* * *} p<0.001$ ) 
metabolize MTS into a formazan salt, measuring the metabolic viability. This metabolic viability cannot be directly compared to cell proliferation as the cells own basal metabolism may be altered due to different parameters (such as: porosity, oxygen and nutrients availability, nature of the substrate where they are growing, etc.) that may or, may not, affect cell proliferation. All together, the morphological analysis, the proliferation and viability results, indicate that the behavior of these cells is improved in the presence of the peptide than the regular gel.

As there are drastic differences on proliferation and cell morphology, it was hypothesized that there were major differences on the secretome of the BM-MSCs encapsulated in the native GG and the modified GG-GRGDs, as well as its effects on neural cell populations. In order to test this, conditioned media (CM) obtained from the BM-MSCs encapsulated in the different forms of GG was used to culture hippocampal derived cells for seven days, without the addition of any other supplements. Results revealed that the proliferation of neuronal cultures was significantly higher $(p<0.05)$ when cultured in the presence of the BM-MSCs/GRGDSmodulated CM (Fig. 2b). Similar results were also obtained for cell metabolic viability. Interestingly, immunocytochemistry analysis revealed that the secretome derived from BM-MSCs/GG was unable to maintain the neurons (MAP-2 positive cells) in culture whereas the BM-MSCs cultured into the GRGDS-GG were able to secrete factors that allowed the survival of neuronal cells (Figs. $2 \mathrm{~d}$ and 3 ). The higher proliferation and cell densities obtained probably lead to an increase of the secreted factors or vesicles, present in the conditioned media. However, the absence of neurons in the cultures incubated with the secretome derived from BM-MSCs encapsulated into the unmodified gellan gum cannot be explained solely by the differences in cell number. We previously demonstrated that in 2D cultures MSCs incubated at 18,750125,000 cells $/ \mathrm{ml}$ were able to secrete factors that promote the survival of hippocampal neurons [10]. In this study we cultured the MSCs in 3D at $125,000 \mathrm{cell} / \mathrm{ml}$ on day zero allowing them to growth for 7 days. So, even with a high concentration of cells per milliliter of culture medium, the MSCs incubated on the unmodified hydrogel were unable to condition the medium with secreted factors in a way that had a positive effect on neurons. In this sense, by comparing to previously $2 \mathrm{D}$ results, we believe that the presence of the peptide on the hydrogel had a crucial influence on the factors secreted by the cells.

As far as we know, there is no literature relating fibronectinderived peptides and the secretome of any system. However, it is well described that the GRGDS peptide binds to integrins on the cell membrane and enhances cell adhesion and migration [27]. We believe that the effect of the GRGDS peptide on the secretome is indirect. Looking to the morphologic differences between the cells culture in unmodified and modified hydrogels, it is expected that the intracellular machinery of the BM-MSCs is also affected, influencing in this way the factors secreted by the cells. As described by Martin Schwartz [28] "Integrins receive signals from other receptors that lead to activation of ligand binding (inside-out signaling) and matrix assembly. Upon binding ligands, they also activate intracellular signaling pathways. These signals converse with pathways that are initiated by soluble ligands to regulate cell

\section{a)}

c)
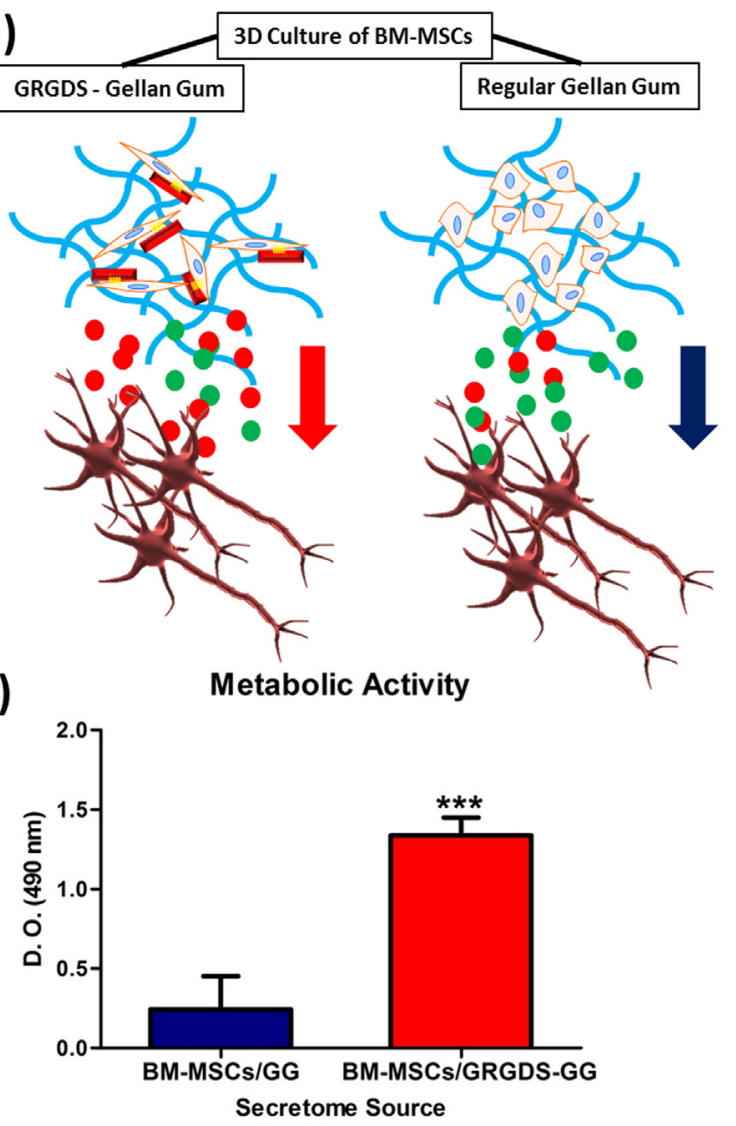

b)

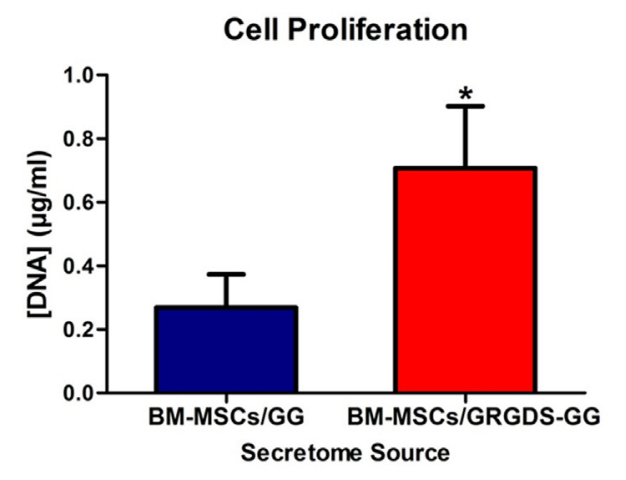

d)

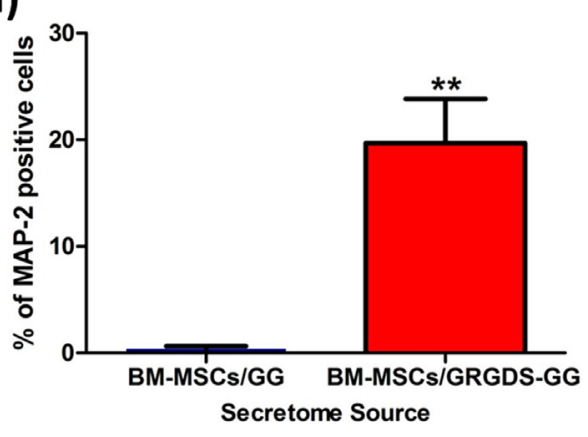

Fig. 2. The effects of BM-MSCs secretome on neuronal cultures. (a) Factors derived from BM-MSCs, cultured either on peptide modified or regular gellan gum hydrogel, where incubated with hippocampal neurons for 7 days. The secretome of cells cultured on GRGDS-GG significantly promoted higher (b) proliferation, (c) activity and (d) survival of neuronal cells than the secretome shaped by cells encapsulated on regular gellan gum. Values are shown as mean \pm standard deviation $\left(n=3\right.$ samples of $1 \times 10^{5}$ cells/sample, $\left.{ }^{*} p<0.05 ;{ }^{* *} p<0.01 ;{ }^{* * *} p<0.001\right)$. 

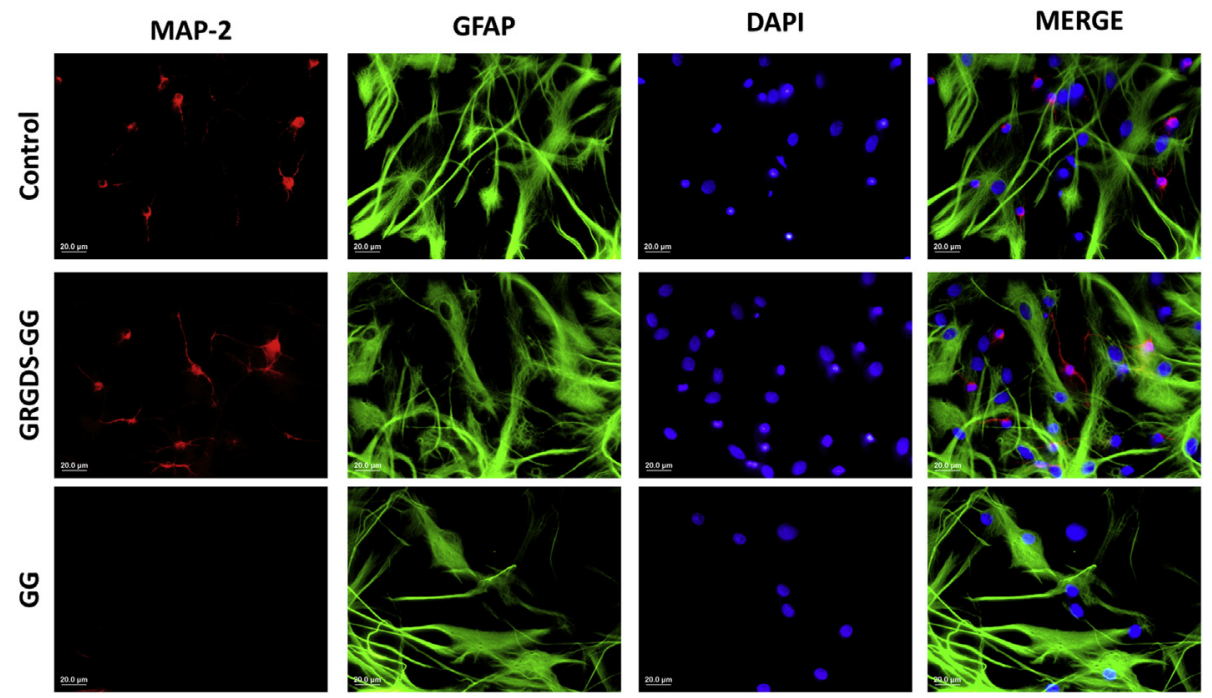

Fig. 3. The effects of the secretome of BM-MSCs, cultured either on peptide modified or regular gellan gum hydrogel, on neurons. In the absence of the GRGDS peptide, BM-MSCs secreted factors which had a detrimental effect on neurons, leading to their death. Neurons (red) and astrocytes (green) were identified by immunocytochemistry against MAP-2 and GFAP, respectively. Nuclei (blue) were counterstained with DAPI.

functions. In this way, cell adhesion is coordinated with other events to orchestrate complex cellular behavior". Therefore, the drastic differences on BM-MSCs' morphology are expected to have played a role on the observed results.

Further studies should now focus on characterizing the changes in the secretome induced by 2D and 3D cultures, using proteomic based analysis.

\section{Conclusions}

These results show the importance of chemical cues, namely those mimicking ECM, within hydrogels in order to adapt BM-MSCs response and secretome to the desired needs. Indeed by grafting a fibronectin-based peptide within the hydrogel in which the cells were cultured, it was possible to positively impact their proliferation and morphology. The latter had obvious effects on the secretome of BM-MSCs allowing it to better support the survival and differentiation of hippocampal neurons. Future work will be focused on the application of GG-GRGDS hydrogel in combination with BM-MSCs in neuro-regeneration strategies.

\section{Acknowledgments}

We would like to acknowledge the funds attributed by the Portuguese Foundation for Science and Technology (FCT) (Grant № PTDC/SAU-BMA/114059/2009; pre-doctoral fellowships to N.A. Silva, SFRH/BD/40684/2007; Ciência 2007 Program to A.J. Salgado; PEst-C/SAU/LA0001/2013-2014 and RNEM-REDE/1506/REM/2005). This work was partially funded by EU-FP7-Health-2011-Collaborative Project 278612, Biohybrid - Templates for Peripheral Nerve Regeneration, and co-funded by Programa Operacional Regional do Norte (ON.2 - O Novo Norte), ao abrigo do Quadro de Referência Estratégico Nacional (QREN), através do Fundo Europeu de Desenvolvimento Regional (FEDER).

\section{References}

[1] B.E. Strauer, M. Brehm, T. Zeus, M. Köstering A. Hernandez, R.V. Soro G. Kögler, P. Wernet, Repair of infarcted myocardium by autologous intracoronary mononuclear bone marrow cell transplantation in humans, Circulation 106 (2002) 1913-1918.
[2] S.P. Bruder, A.A. Kurth, M. Shea, W.C. Hayes, N. Jaiswal, S. Kadiyala, Bone regeneration by implantation of purified, culture-expanded human mesenchymal stem cells, J. Orthop. Res. 16 (1998) 155-162.

[3] C.P. Hofstetter, E.J. Schwarz, D. Hess, J. Widenfalk, A. El Manira, D.J. Prockop, L. Olson, Marrow stromal cells form guiding strands in the injured spinal cord and promote recovery, PNAS 99 (2002) 2199-2204.

[4] S. Wakitani, K. Imoto, T. Yamamoto, M. Saito, N. Murata, M. Yoneda, Human autologous culture expanded bone marrow mesenchymal cell transplantation for repair of cartilage defects in osteoarthritic knees, Osteoarthr. Cartil. 10 (2002) 199-206.

[5] M. Rojas, J. Xu, C.R. Woods, A.L. Mora, W. Spears, J. Roman, K.L. Brigham, Bone marrow-derived mesenchymal stem cells in repair of the injured lung, Am. J. Respir. Cell. Mol. Biol. 33 (2005) 145-152.

[6] Y. Izuta, M. Ochi, N. Adachi, M. Deie, T. Yamasaki, R. Shinomiya, Meniscal repair using bone marrow-derived mesenchymal stem cells: experimental study using green fluorescent protein transgenic rats, Knee 12 (2005) 217-223.

[7] F. Teixeira, M. Carvalho, N. Sousa, A. Salgado, Mesenchymal stem cells secretome: a new paradigm for central nervous system regeneration? Cell. Mol. Life Sci. (2013) in press.

[8] N.A. Silva, J.M. Gimble, N. Sousa, R.L. Reis, A.J. Salgado, Combining adult stem cells and olfactory ensheathing cells: the secretome effect, Stem Cells Dev. (2013), http://dx.doi.org/10.1089/scd.2012.0524 (Epub ahead of print).

[9] N. Nakano, Y. Nakai, T.-B. Seo, Y. Yamada, T. Ohno, A. Yamanaka, Y. Nagai, M. Fukushima, Y. Suzuki, T. Nakatani, C. Ide, Characterization of conditioned medium of cultured bone marrow stromal cells, Neurosci. Lett. 483 (2010) 57-61.

[10] C. Ribeiro, J. Fraga, M. Grãos, N. Neves, R. Reis, J. Gimble, N. Sousa, A. Salgado, The secretome of stem cells isolated from the adipose tissue and Wharton jelly acts differently on central nervous system derived cell populations, Stem Cell Res. Ther. 3 (2012) 1-7.

[11] A.L Oliveira, E.C. Sousa, N.A. Silva, N. Sousa, A.J. Salgado, R.L. Reis, Peripheral mineralization of a 3D biodegradable tubular construct as a way to enhance guidance stabilization in spinal cord injury regeneration, J. Mater. Sci. Mater. Med. 23 (2012) 2821-2830.

[12] N.A. Silva, R.A. Sousa, A.O. Pires, N. Sousa, A.J. Salgado, R.L. Reis, Interactions between Schwann and olfactory ensheathing cells with a starch/polycaprolactone scaffold aimed at spinal cord injury repair, J. Biomed. Mater. Res. Part A 100A (2012) 470-476.

[13] X. Yang, R.S. Tare, K.A. Partridge, H.I. Roach, N.M.P. Clarke, S.M. Howdle, K.M. Shakesheff, R.O.C. Oreffo, Induction of human osteoprogenitor chemotaxis, proliferation, differentiation, and bone formation by osteoblast stimulating factor-1/pleiotrophin: osteoconductive biomimetic scaffolds for tissue engineering, J. Bone. Miner. Res. 18 (2003) 47-57.

[14] N.A. Silva, R.A. Sousa, J.S. Fraga, M. Fontes, H. Leite-Almeida, R. Cerqueira, A. Almeida, N. Sousa, R.L. Reis, A.J. Salgado, Benefits of spine stabilization with biodegradable scaffolds in spinal cord injured rats, Tissue Eng. Part C 19 (2012) 101-108.

[15] G. Perale, F. Rossi, E. Sundstrom, S. Bacchiega, M. Masi, G. Forloni, P. Veglianese, Hydrogels in spinal cord injury repair strategies, ACS Chem. Neurosci. 2 (2011) 336-345.

[16] D.R. Nisbet, K.E. Crompton, M.K. Horne, D.I. Finkelstein, J.S. Forsythe, Neural tissue engineering of the CNS using hydrogels, J. Biomed. Mater. Res. Part B 87B (2008) 251-263. 
[17] K. Ma, A.L. Titan, M. Stafford, C.h. Zheng, M.E. Levenston, Variations in chondrogenesis of human bone marrow-derived mesenchymal stem cells in fibrin/ alginate blended hydrogels, Acta Biomater. 8 (2012) 3754-3764.

[18] A. Flausse, C. Henrionnet, M. Dossot, D. Dumas, S. Hupont, A. Pinzano, D. Mainard, L. Galois, J. Magdalou, E. Lopez, P. Gillet, M. Rousseau, Osteogenic differentiation of human bone marrow mesenchymal stem cells in hydrogel containing nacre powder, J. Biomed. Mater. Res. Part A (2013) in press, http:// www.ncbi.nlm.nih.gov/pubmed/?term=flausse $+a+2013$.

[19] B. Sun, W. Ma, F. Su, Y. Wang, J. Liu, D. Wang, H. Liu, The osteogenic differentiation of dog bone marrow mesenchymal stem cells in a thermo-sensitive injectable chitosan/collagen/ $\beta$-glycerophosphate hydrogel: in vitro and in vivo, J. Mater. Sci. Mater. Med. 22 (2011) 2111-2118.

[20] J.T. Oliveira, L. Martins, R. Picciochi, P.B. Malafaya, R.A. Sousa, N.M. Neves, J.F. Mano, R.L. Reis, Gellan gum: a new biomaterial for cartilage tissue engineering applications, J. Biomed. Mater. Res. Part A 93A (2010) 852-863.

[21] J.T. Oliveira, L.S. Gardel, T. Rada, L. Martins, M.E. Gomes, R.L. Reis, Injectable gellan gum hydrogels with autologous cells for the treatment of rabbit articular cartilage defects, J. Orthop. Res. 28 (2010) 1193-1199.

[22] J. Silva-Correia, J.M. Oliveira, S.G. Caridade, J.T. Oliveira, R.A. Sousa, J.F. Mano, R.L. Reis, Gellan gum-based hydrogels for intervertebral disc tissueengineering applications, J. Tissue Eng. Regener. Med. 5 (2011) e97-e107.
[23] N.A. Silva, M.J. Cooke, R.Y. Tam, N. Sousa, A.J. Salgado, R.L. Reis, M.S. Shoichet, The effects of peptide modified gellan gum and olfactory ensheathing glia cells on neural stem/progenitor cell fate, Biomaterials 33 (2012) 6345-6354.

[24] N.A. Silva, A.J. Salgado, R.A. Sousa, J.T. Oliveira, A.J. Pedro, H. Leite-Almeida, R. Cerqueira, A. Almeida, F. Mastronardi, J.F. Mano, N.M. Neves, N. Sousa, R.L. Reis, Development and characterization of a novel hybrid tissue engineering based scaffold for spinal cord injury repair, Tissue Eng. Part A 16 (2010) 45-54.

[25] S.R. Cerqueira, J.M. Oliveira, N.A. Silva, H. Leite-Almeida, S. Ribeiro-Samy, A. Almeida, J.F. Mano, N. Sousa, A.J. Salgado, R.L. Reis, Microglia response and in vivo therapeutic potential of methylprednisolone-loaded dendrimer nanoparticles in spinal cord injury, Small (2012), http://dx.doi.org/10.1002/ smll.201201888.

[26] K.W. Ng, D.T.W. Leong, D.W. Hutmacher, The challenge to measure cell proliferation in two and three dimensions, Tissue Eng. 11 (2005) 182-191.

[27] G. Maheshwari, G. Brown, D.A. Lauffenburger, A. Wells, LG. Griffith, Cell adhesion and motility depend on nanoscale RGD clustering, J. Cell Sci. 113 (2000) 1677-1686.

[28] M.A. Schwartz, M.D. Schaller, M.H. Ginsberg, Integrins: emerging paradigms of signal transduction, Annu. Rev. Cell Dev. Biol. 11 (1995) 549-599. 